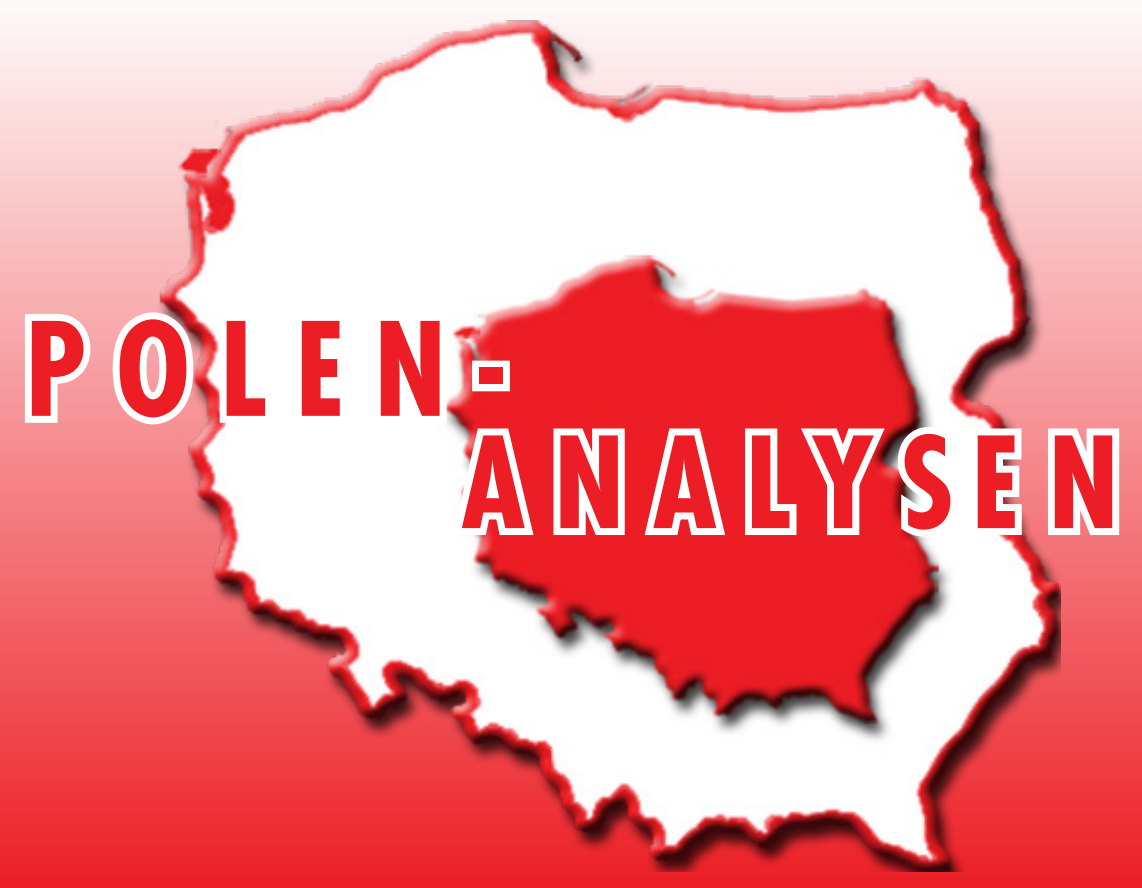

www.laender-analysen.de/polen

\title{
DER NATIONALKATHOLIZISMUS UND DIE DEMOKRATIE
}

\section{ANALYSE}

Der Nationalkatholizismus und die Demokratie

Ireneusz Krzemiński, Warschau

\section{- TABELLEN UND GRAFIKEN ZUM TEXT}

Umfragen zu politischen Entwicklungen

CHRONIK

6. Dezember 2016 - 16. Januar 2017

Herausgegeben mit finanzieller Unterstützung

der Stiftung für deutsch-polnische Zusammenarbeit

FUNDACJA WSPÓŁPRACY

\section{DEUTSCHES POLEN INSTITUT}

- Forschungsstelle Osteuropa an der Universität Bremen 


\section{Der Nationalkatholizismus und die Demokratie}

Ireneusz Krzemiński, Warschau

\section{Zusammenfassung}

In Polen betreibt die regierende Partei Recht und Gerechtigkeit (Prawo i Sprawiedliwość - PiS) eine grundlegende Umgestaltung der politischen Institutionen und des gesellschaftlichen Zusammenlebens, die zu einer tiefen Spaltung in Politik und Gesellschaft bis in Familien und Freundeskreise hinein geführt hat. Die Unterstützung der Hauptströmung der katholischen Kirche für die PiS-Regierung kommt einem relativ großen Segment der polnischen Gesellschaft entgegen und wird von der PiS als Instrument für die eigenen politischen Zwecke medial wirksam genutzt. Die weiterhin stabile Position der PiS weist aber auch auf die fundamentale Schwäche der Opposition hin, die weder mit konstruktiver Kritik noch zukunftsweisenden Ideen und starken Persönlichkeiten in Erscheinung tritt.

$\mathrm{D}$ Antwort auf die Frage, was zurzeit in Polen geschehe, ist sehr einfach und zugleich sehr schwierig. Einfach mit Blick auf die grundlegenden rechtlichen und moralischen Regeln eines demokratischen Staates. Wir haben es mit einer bewussten und zielgerichteten Untergrabung derselben vonseiten der rechtmäßig gewählten Partei Recht und Gerechtigkeit (Prawo i Sprawiedliwość - PiS) zu tun. Gleichzeitig ist die Antwort schwierig, weil unklar ist, wie man sich dem entgegenstellen kann, und schwierig ist auch die Antwort auf eine zweite Frage: Wie ist das möglich in einer Gesellschaft, deren pro-demokratische und pro-westliche Anstrengungen seinerzeit den sowjetischen Kommunismus überwanden? Die ganze Angelegenheit ist demnach komplex.

Umso mehr, als der Anschlag auf die Institutionen und Prinzipien des demokratischen Rechtsstaates unter der Führung eines Menschen vonstattengeht, der sich in der ausdifferenzierten Bewegung für Freiheit und Demokratie engagiert hatte. Obgleich er nie in der ersten Reihe der Freiheits- und Demokratiekämpfer gestanden hatte, spielte er in verschiedenen Phasen des Umbaus Polens eine sehr wichtige Rolle. Möglicherweise ist die Tatsache, dass er nur einer von vielen Aktivisten der Opposition und später der Solidarność-Bewegung und der Solidarność im Untergrund gewesen war, jetzt die Hauptmotivation für seine Aktivitäten als Autorität und Vorsitzender einer Partei, die sich in Richtung autoritäre Regierung bewegt und konsequent den demokratischen Rechtsstaat zerstört.

Die Vision des Staates, von der sich Jarosław Kaczyński leiten lässt, stützt sich auf die Tradition von Ideen, die der Vergangenheit anzugehören schienen. Sie wurden allerdings auf intelligente Weise reaktiviert, unter sehr tatkräftiger Beteiligung der katholischen Kirche. Dies ist ein weiteres Paradox: Wie ist es möglich, dass die Kirche, ohne die der erfolgreiche Kampf der Solidarność-Bewegung um Demokratie schlecht vorstellbar gewesen wäre, jetzt zu einem
Hauptverbündeten des Anschlags auf die Demokratie geworden ist?

\section{Nationaldemokratische Ideologie - neu gebügelt}

Als Bezugsrahmen für die Analyse setze ich die polnische Tradition der sogenannten Nationaldemokratie. Diese ist die ideelle Basis. Pater Tadeusz Rydzyk, der Direktor von »Radio Maryja«, entwickelte und modifizierte auf dieser Grundlage eine Ideologie, die jetzt PiS und Jarosław Kaczyński von Nutzen ist. Ich bin ein entschiedener Verfechter der These, dass Pater Tadeusz Rydzyk eine enorme Rolle als Ideologe des Regierungslagers spielte und spielt, was sowohl die Vorteile belegen, die ihm die PiS-Regierung bereits verschafft hat, als auch die Rolle, die er jetzt bei der Unterstützung der Machthaber spielt. Pater Rydzyk hat die Ideen Roman Dmowskis (1864-1939), des Chefideologen der Nationaldemokratie, intelligent und einfallsreich umgestaltet. Die Vision vom Staat, wie sie Dmowski vertrat, setzt den nationalen Diskurs als absolut vorrangig über alle anderen Diskurse. Die Sorge um den guten Ruf der Nation und des Nationalstaates sollte die Diskussionsfreiheit und andere bürgerlichen Freiheiten wesentlich eingrenzen. Die moralische Haltung eines guten Polen bestehe darin, die eigene Nation zu bejahen und interne Kritik zu beschränken, wenn sie den guten Ruf Polens gefährden könnte. Nationale Minderheiten sollten solange nicht in Gänze die Bürgerrechte erhalten, bis sie sich vollständig assimiliert hätten, was in der Praxis die Annahme des Katholizismus bedeutete. Die Verbindung zwischen der Nation und der Kirche ist hier also sehr stark. Die katholische Kirche wird dabei als eine der größten Autoritäten für den Erhalt des nationalen Geistes betrachtet. Der größte ideelle Feind Dmowskis und der Nationaldemokratie war der Liberalismus, der vor allem auf die Rechte und die bürgerlichen Freiheiten bezogen wurde und als Ausschaltung der intervenierenden Funktionen des Staates bei der Regulierung der Lebensstile der 
Bürger verstanden wurde. Dies ist natürlich ein Postulat, das in einer modernen, liberalen Demokratie und einem Rechtsstaat nicht aufrechtzuerhalten ist. Jedoch ergibt sich aus jenem Verständnis eine recht einsichtige Schlussfolgerung: In einem echten Nationalstaat sollte die Macht von einer Nationalpartei ausgeübt werden, die sich auf Autoritäten stützt - so auch auf die Autorität der Kirche-, um die nationalen Interessen umzusetzen. Die Vision von der Welt und den nationalen Beziehungen stützte sich auf die Ideen des sozialen Evolutionismus. Die Beziehungen zwischen den Nationen wurden also als fortwährender Konkurrenzkampf beschrieben und als Ziel galt die Realisierung der egoistischen nationalen Interessen. Die Pflicht des Nationalstaates sollte daher der Kampf um die eigenen Interessen sein, und er sollte sich weder den Sentimentalitäten noch Illusionen von internationaler Freundschaft und Zusammenarbeit hingeben. Dmowski kritisierte sehr heftig die polnische Ausprägung der Romantik; der romantischen Tradition entsprechend galt es als wichtiger, moralische Pflichten und Werte der Nation zu erfüllen als das Handeln an aktuellen praktischen Interessen auszurichten. Die romantischen Ideale hatten ein martyrologisches Bild der Nation zur Folge, und Niederlagen wurden in moralische Siege der Polen umgedeutet. Dmowski wies diese Ideale entschieden zurück: Die Nation müsse in Konkurrenz mit anderen siegen und die Beziehungen zu den anderen als Mittel und rein pragmatisch behandeln.

Der Ideologe von »Radio Maryja« und der PiS, Pater Rydzyk, distanzierte sich allerdings radikal von dem so entschieden vollzogenen Ausschluss des romantischen Leidens. Erstens: Dmowski lehnte die Idee des polnischen Messianismus und der Rolle der Polen als "Christus der Nationen« ab. Diese Idee hat für die Angehörigen der Kirche freilich eine sehr große Anziehungskraft. Zweitens: Die Berufung auf die polnische Nation (pardon: Polnische Nation) baut die polnische Identität enorm auf. Die Polen litten unter den Deutschen und den Russen bzw. der UdSSR. Ihr Leiden wird nicht anerkannt, denn die ganze Welt weint nur über den Holocaust der Juden. Das polnische Leiden muss also der Welt präsentiert werden. Mehr noch, der polnische Staat wurde von den europäischen Verbündeten verraten, was den Polen erlaubt, ihnen heute Forderungen zu stellen. Wenn sich nun also Europa vereinigt hat, wenn es so der Verbrechen an den Juden gedenkt und nach gegenseitiger Versöhnung strebt, dann haben die Polen auch das Recht, etwas für sich selbst zu fordern. Daraus resultierte die Forderung, dass sich Europa nicht zu sehr in die Angelegenheiten des polnischen Staates einmischen solle. Endlich WIEDER FREI! Hier liegt der Ursprung der Haltung, dass sich Polen "von den Knien erhebt«.
Es wird von dem Einfluss der Politischen Theologie Carl Schmitts, des Autors der juristischen Rechtfertigung einer diktatorischen Macht (zum Beispiel Hitler), auf Jarosław Kaczyński gesprochen. Zweifellos gefiel es einer Gruppe sogenannter polnischer Konservativer, einige Schriften Carl Schmitts herauszugeben; zuletzt erschien "Die Diktatur» (Dyktatura, Warszawa 2016). Bestimmte Begriffe, die PiS in ihrem Diskurs verwendet und die in Kaczyńskis Äußerungen auftauchen, allen voran der berühmte »Souverän« als Subjekt der Änderungen der Normen und Rechte, können dies bestätigen.

Mit Sicherheit sind die selbstherrlichen gesetzgeberischen Aktivitäten, die das bisher geltende Recht und die Verfassung komplett ignorieren, ideologisch begründet, aber es ist dies keine Ideologie, die sich leicht enthüllen lässt. Die einheitliche Sprache, deren sich die Vertreter der regierenden Partei bedienen, und die beträchtliche Ladung von Emotionen, schlechten Emotionen, die dem umfassenden und bis heute ungestörten Angriff auf denjenigen Staat dienen, der nach 1989 aufgebaut wurde, sowie auf alle bisherigen Politiker, zeigen eindrücklich, dass die PiS-Vertreter eine gemeinsame Ideologie verbindet. Es handelt sich sicherlich nicht nur um die Ideologie Pater Rydzyks, obgleich "Radio Maryja» seit langem an der Veränderung der Bedeutung von "Demokratie«, »Freiheit des Staates« oder »bürgerlichen Freiheiten " arbeitet, und zwar in einer Richtung, die der Begründung der widerrechtlichen und außerrechtlichen Tätigkeiten von PiS sehr dient. Allgemein verbreitet ist die Rechtfertigung dieses Handelns als Realisierung des »richtigen«, moralisch begründeten gesellschaftlichen und nationalen Interesses. Alle, die anderer Meinung sind, werden zu Feinden und Verrätern. Diese sind natürlich nicht imstande, dem Vaterland gut zu dienen, so dass ihre Stimmen ausgeschlossen werden müssen. Die PiS-Regierung hat den politischen Streit in einen Krieg verwandelt, der Feindseligkeit und Hass eine Stimme gibt. Daraus ergeben sich düstere Konsequenzen, sowohl im Verhältnis zu den »eigenen anderen" als auch zu allen, die anders sind. An deren Spitze stehen zurzeit die Flüchtlinge und alle Moslems. Die Anzahl der Überfälle auf Menschen, die eine andere Hautfarbe haben und die verdächtigt werden, dem Islam anzuhängen, wächst beunruhigend.

\section{Instrumente der Regierung}

Die populistischen Versprechungen und Geschenke der Regierung weisen die angebliche "Glaubwürdigkeit" ihrer gemachten Versprechen und ihre eindeutig "guten Absichten" gegenüber der Nation aus. Die wichtigste Gabe des Staates, das Familienförderprogramm "500 plus« für Familien mit mehreren Kindern, verbesserte mit Sicherheit die Lebenssituation einer bestimm- 
ten Kategorie Familie. Gleichzeitig wurden jedoch die Schwierigkeiten alleinerziehender Mütter mit ihren Kindern, insbesondere wenn sie nur eines haben, vollkommen außer Acht gelassen. Auch die alleinerziehenden Väter, von denen es in Polen weniger gibt, blieben unbeachtet. Aber «alle«, einschließlich derjenigen, die ein hohes Einkommen haben, profitieren von den "500 plus«. Es ist also schwer, den populistischen und wahlkampftauglichen Charakter dieses Programms zu bestreiten.

Manche Politologen behaupten, dass die Aktivitäten von $P i S$ von chaotischen Entscheidungen diktiert seien. Das wiederholen auch Journalisten. Dieses Urteil ist vollkommen falsch und irreführend. Die Aktivitäten von PiS, vielmehr die Entscheidungen des Präses Jarosław Kaczyński, sind hervorragend durchdacht und konsequent, sowohl strategisch als auch taktisch. Von außerordentlicher Bedeutung war der Angriff auf die öffentlichen Medien, das öffentliche Fernsehen und Radio. Die dort eingesetzte Propagandasprache erinnert lebhaft an die schlimmsten Jahre des Kommunismus - an die Medien der Gomułka-Ära nach 1968 und an die Zeit des Kriegsrechts, das am 13. Dezember 1981 verhängt wurde. Es schien, als könne diese Art von Propaganda im Zeitalter des Internet und der Vielzahl der Medien, die relativ in Ruhe gelassen wurden, für die Wissens- und Meinungsbildung der Bürger nicht gefährlich werden. Indessen war die Entscheidung, die öffentlichen Medien der Propaganda zu unterstellen, außerordentlich richtig für die Regierung. Im Juni 2015 nutzten 15,9 Mio. Empfänger das terrestrische Fernsehen, für 11,5 Mio. war es das einzige zugängliche Fernsehsignal. Im allgemein zugänglichen Angebot dominieren die Sender des öffentlichen Fernsehens, u. a. der Informationssender "TVP Info", dessen propagandistische Bedeutung enorm ist. Die privaten TV-Sender, die zum Angebot gehören, sind kommerzielle Sender, das heißt, sie dienen der Unterhaltung. Auch wenn Sender wie »TVN« und "Polsat" ihre Nachrichtensendungen bringen, gehen sie im Strom der Informationsprogramme des Fernsehens unter, das PiS das "nationale« nennt. Die Informationskanäle jener Sender, also »tvn24", "Polsat News« oder »Polsat News 2 «, werden nur über kostenpflichtige Fernsehsender angeboten. Das heißt, Millionen Menschen werden hauptsächlich von den propagandistischen, verlogenen "nationalen« Medien erreicht.

\section{Anhänger und andere Wähler von PiS}

Wenn man die Unterstützung für die PiS-Regierung analysiert, das Meinungsforschungsinstitut CBOS hat entsprechende Untersuchungen durchgeführt, dann zeigt sich, dass trotz aller populistischer Präsente für die Bürger die Unterstützung für $P i S$ praktisch unverändert auf dem Niveau geblieben ist, das sie bei ihrem Wahlsieg erreicht hatte. Mit Sicherheit ist dies ein Erfolg der PiSRegierung: Bisher war die Unterstützung für eine regierende Partei nach einem Jahr Amtszeit nie auf der Höhe geblieben, die in den Wahlen erlangt worden war. Aber recht unverändert bleiben auch andere wichtige Indizes. In einer Befragung einen Monat nach den Wahlen sank die Bedeutung der vorher regierenden Bürgerplattform (Platforma Obywatelska - PO) deutlich und oszilliert seitdem um diesen Wert. Die neue Partei von Ryszard Petru, Die Moderne (Nowoczesna), die einen Monat nach den Wahlen deutlich an Zustimmung gewann, bewegt sich seit Januar 2016 in einer Spanne von 14-19 Prozent. Die Unterstützung für die Regierung und Ministerpräsidentin Beata Szydło hält sich auf einem stabilen Niveau, wobei sie immer noch ebenso viele Gegner wie Sympathisanten hat. Die Daten zeigen, dass Polen in zwei Lager gespalten ist, die sich in ihren politischen Präferenzen und Urteilen verschanzen. Zwei Dinge sollten hier betrachtet werden:

Erstens: Wer sind die Anhänger der regierenden Partei (die im Grunde eine Koalition ist, da zur Regierungsmannschaft auch Vertreter der Fraktion der Vereinigten Rechten (Zjednoczona Prawica) gehören)? Die Antwort ist nicht schwierig, wenn man die Untersuchungen von CBOS als Grundlage nimmt. Vor allem sind es Landbewohner, Ältere (mindestens 55 Jahre alt), mit Grundschul-, Mittelschul- oder Berufsschulbildung und niedrigem Einkommen. Am häufigsten sind es Bauern, Rentner und an nächster Stelle Arbeiter. Sie stellen zirka 50 Prozent der PiS-Anhänger. Dies sind zu einem hohen Anteil Menschen, die die kostenlosen, allgemein zugänglichen Medien nutzen. Natürlich mögen die reicheren Landwirte eine Satellitenschüssel haben, aber ältere Bauern haben diese selten. Ähnlich ist es in Kleinstädten, wo das Kabelfernsehen im Allgemeinen nicht in die alten, armen Stadtviertel oder die Stadtteile mit Einfamilienhäusern reicht. Alle diese Menschen sehen mit Sicherheit das nationale Fernsehen, das mit politischer PiS-Propaganda gesättigt ist und nicht nur ein negative, sondern eine klar feindliche Haltung gegenüber allen Kritikern und Gegnern der regierenden Partei aufbaut.

Die Gegner von PiS sind wiederum Bewohner von Städten mit mehr als 100.000 Einwohnern mit recht hohen Gehältern (2.000 Zloty und mehr), Hochschulabsolventen und Menschen im Alter von 25 bis 45 Jahren. Sie sind das Publikum der unabhängigen, privaten Informationssender im Fernsehen und der Presse, die noch ihre Unabhängigkeit bewahrt, trotz solcher Aktionen von PiS, wie beispielsweise das Abonnement der wichtigsten oppositionellen Tageszeitung "Gazeta Wyborcza» in öffentlichen Institutionen zu 
verbieten sowie deren Verkauf an Tankstellen des Orlen-Konzern.

Małgorzata Omyła-Rudzka hat in einer CBOSUntersuchung (Komunikat z Badań Nr 156/2016) festgestellt, dass "auf die erklärte Unterstützung für die Regierung an erster Stelle jedoch die Weltanschauung Einfluss hat. Mit dem Kabinett von Beata Szydło identifizieren sich deutlich häufiger diejenigen Befragten, die mehrmals wöchentlich religiös praktizieren (70 Prozent), sowie diejenigen mit rechten politischen Ansichten (67 Prozent). Abneigung der Regierung gegenüber geben häufiger diejenigen an, die nicht religiös praktizieren (58 Prozent) und sich mit dem linken politischen Spektrum identifizieren (61 Prozent).

Die oben genannte Kategorie der PiS-Anhänger auf dem Land und in den Kleinstädten deckt sich mit denen, deren Weltanschauung katholisch-national orientiert ist. Natürlich gibt es auch viele laute Anhänger und Bekenner solcher Ansichten in der großstädtischen Intelligenz, aber dort sind sie deutlich in der Minderheit. Analysen von Soziologen stellen immer häufiger die Tatsache heraus, dass die ländlich-kleinstädtische Wählerschaft von PiS sehr stabil ist. Für mich besteht kein Zweifel, dass die Unterstützung der katholischen Kirche PiS diese Stabilität in hohem Maße garantiert. Der TV-Sender »Trwam«, Teil des medialen Königreichs von Pater Rydzyk, ist auch auf der allgemein zugänglichen Medienplattform angesiedelt und »Radio Maryja « funkt mit ebensolcher Reichweite wie das Erste Programm des Polnischen Radio.

Der Wahlsieg von $P i S$, der die parlamentarische Mehrheit einbrachte und die Bildung einer Alleinregierung zuließ, war allerdings nur möglich, weil über den harten Kern der PiS-Wählerschaft hinaus noch einige Prozent mehr Wählerstimmen gewonnen werden konnten. Darunter befanden sich, worauf schon öfter hingewiesen wurde, auch junge Menschen, die von der PORegierung enttäuscht waren bzw. keine Perspektive für sich unter einer Fortsetzung der Koalition aus PO und Polnischer Bauernpartei (Polskie Stronnictwo LudowePSL) sahen. Diese Koalition hatte die Regierungsverantwortung zwei Legislaturperioden lang ausgeübt, so dass die jungen Wähler keine Erfahrungen mit einer anderen Regierung hatten - und auch nicht mit der PiS-Regierung der Jahre 2005 bis 2007, deren Amtszeit durch vorgezogene Neuwahlen verkürzt worden war. Viele Wähler der Bürgerplattform waren bereits zwei Jahre vor den Parlamentswahlen 2015 von ihrer Partei enttäuscht. Im Allgemeinen zogen sich sogar die politisch Engagierten zurück, unterstützen auch keine andere Partei und gaben an, kein Verlangen zu haben, zur Wahl zu gehen. Zu keinem Zeitpunkt gelang es der Bürgerplattform während des fatalen Präsidenten- und
Parlamentswahlkampfes, die Unterstützung ihrer ehemaligen Anhänger zurückzugewinnen.

Hier fügt sich der zweite Aspekt an: Wie bereits gesagt, ist die sich seit einem Jahr konstant haltende Unterstützung für die regierende Partei bemerkenswert. Früher sank gewöhnlich die Unterstützung in größerem oder geringerem Maße und wuchs die Unterstützung für die Oppositionsparteien, insbesondere für die größte von ihnen. Zurzeit haben wir es mit einer überraschend beständigen Verteilung der Anteile zu tun. Das weist nicht nur auf den Erfolg der regierenden PiS hin, ihre Wähler bei sich zu halten, sondern vor allem auf die Schwäche der Opposition.

\section{Schwache und uneinige Opposition}

Ein sehr gutes Beispiel ist hier die außerordentlich angespannte Situation im polnischen Parlament seit dem 16. Dezember 2016. Die Abgeordneten der Opposition, die sich schließlich zusammentaten, entschieden sich, gegen den unerhört dreisten Ausschluss eines PO-Abgeordneten aus der Parlamentssitzung durch den Sejmmarschall zu protestieren. Daraufhin verlegte PiS die Sitzung in einen anderen Saal, den sogenannten Säulensaal, und verabschiedete dort eines der wichtigsten Gesetze überhaupt, das Haushaltsgesetz, wobei sie viele Parlamentarier der Opposition nicht in diesen Saal hinein ließ. Diese also protestierten im Plenarsaal des Sejm und teilten mit, dass die Beratungen des Sejm vom 16. Dezember offiziell nicht beendet wurden. Diese Aktion der Opposition rief in der Hauptstadt ein ungewöhnlich lebhaftes Echo hervor. Hinzu kommt, dass es auch um die geplante Neuregelung der Regierung ging, die Journalisten des Parlamentsgebäudes zu verweisen und sie in einem Nachbargebäude unterzubringen. Dort sollten sie sich lediglich über die Geschehnisse im Plenarsaal informieren lassen und sich nach vorheriger Vereinbarung mit Abgeordneten treffen können. Bereits in dieser Angelegenheit hatte es eine Welle gesellschaftlicher Proteste gegeben, aber die unkontrollierte Abstimmung des Haushaltsgesetzes für das Jahr 2017 löste sofort den spontanen Protest der Warschauer aus. Am Abend des 16. Dezember versammelten sich Tausende vor dem Sejm. An den folgenden Tagen fanden trotz des schlechten Wetters in allen großen Städten zahlreiche vom Komitee zur Verteidigung der Demokratie (Komitet Obrony Demokracji-KOD) organisierte Demonstrationen statt. Allerdings ereignete sich dies alles unmittelbar vor den Weihnachtsfeiertagen, die in der polnischen Kultur eine große Rolle spielen; daran schloss sich der Jahreswechsel an - die Leidenschaft, sich an Demonstrationen zu beteiligen, flaute so zwangsläufig ab.

Der 11. Januar 2017 und die Eröffnung der Parlamentssitzung war mit großer politischer Anspannung 
verbunden. Erstens: Die vereinigte Opposition, die Abgeordneten der $P O$ und der Modernen, die gemeinsam den Plenarsaal des Sejm besetzt hatten, trennten sich wieder. Ryszard Petru, Parteichef der Moderne, ein vollkommen unerfahrener Politiker, beschloss praktisch das Ende der Besetzung, was den PO-Vorsitzenden Grzegorz Schetnya veranlasste deutlich zu machen, um was es der Opposition eigentlich geht. Leider wurde das Haushaltsgesetz, das im Dezember rechtswidrig vom Parlament verabschiedet worden war, von der Zweiten Parlamentskammer, dem Senat, unverändert angenommen. Es blieb nichts anderes übrig, als auf die weitere Besetzung des Plenarsaals zu verzichten und andere Aktivitäten zu versprechen. Alles weist darauf hin, dass während der knapp vier Wochen dauernden Protestbesetzung weder die Oppositionsführer noch die protestierenden Parlamentarier ein konsequentes Handlungskonzept entwickelt haben.

Zweitens: Erneut tritt die Kirche aufs Spielfeld und ihre Unterstützung für die regierende Partei, die immer drastischer die Verfassung und das geltende Recht bricht. Die Protestierenden kamen nicht auf die Idee, beispielsweise einen Bischof oder zumindest einen Priester einzuladen, was sich angeboten hätte, da die Besetzung auch über die Weihnachtsfeiertage dauerte. Anstatt den Abgeordneten der Opposition Unterstützung zu signalisieren oder ihnen einen Besuch abzustatten, verkündete jedoch der Metropolit von Warschau, Kazimierz Nycz, dass man die Weihnachtsfeiertage zu Hause verbringen sollte. Hierin zeigt er seinen notorisch fehlenden Mut. Allerdings hätte auch ein anderer Geistlicher eingeladen werden können, ich bin sicher, dass sich ein Priester bereit erklärt hätte, die Einladung der protestierenden Parlamentarier anzunehmen. Eindrucksvoll war der Auftritt von Bischof Tadeusz Pieronek im Fernsehsender "tvn24", der den Bruch der Verfassung und des geltenden Rechts durch die Regierung deutlich kritisierte. Es hätte also jemanden gegeben, an den sich die Opposition hätte wenden können, aber da dies nicht getan wurde, ging die Gelegenheit verloren, wichtige Unterstützung zu erhalten.

Die Schwäche der Opposition besteht unter anderem darin, dass sie nicht mit eigenen Vorschlägen auftritt. Angeblich soll Grzegorz Schetyna, der Parteivorsitzende der $P O$, ein "Schattenkabinett« berufen haben, das nach britischem Muster die Entscheidungen der Regierung kommentieren und Änderungen fordern soll. Bisher kam es noch nicht dazu, und das Schattenkabinett scheint im Schatten versunken zu sein.

Die Gemengelage ist nicht einfach. Sie betrifft auch die Bürgerbewegung, die sich um $K O D$ herum gebildet hat. Diese soziale Bewegung hat bereits offiziell einen Verband gegründet, der die Koordination aller Reaktio- nen auf weitere, rechtswidrige Aktionen der regierenden Partei übernimmt. Die ursprüngliche Parole, die Verteidigung des Verfassungstribunals, die dazu führte, dass die Protestbewegung entstand, wird allerdings gerade Geschichte. Nach einem Jahr Kampf (und Passivität des Staatspräsidenten) ist es PiS gelungen, sich das Verfassungstribunal unterzuordnen. Die Proteste haben nicht geholfen, obgleich die Bürger viele Gelegenheiten hatten und sicherlich auch in Zukunft haben werden, ihren Widerspruch gegen die undemokratischen und antidemokratischen Maßnahmen der Regierung zu demonstrieren. Es fehlt dabei allerdings eine Idee, die nicht nur bei der Verteidigung der bisherigen Staatsordnung stehen bleibt. Auch wenn es sich um die Verteidigung der grundlegenden Werte, der moralischen und ethischen Werte einer demokratischen Gesellschaft handelt, sind Ideen oder konkrete Änderungsvorschläge notwendig, die den Regierenden entgegengestellt werden, neue Horizonte eröffnen sowie neue Chancen für eine Gesellschaft, die die liberale Demokratie verteidigt. Hier ist auch konstruktive Kritik erforderlich, die in die Zukunft weist. Die Menschen müssen erfahren, dass sich ihr Protest in einen Prozess des Aufbaus, der Gestaltung einer Ordnung verwandeln kann, einer Ordnung, die besser ist als das, was war und was ja vergleichsweise leicht zu zerstören war. Auch denkt niemand darüber nach, wie man die erreichen könnte, die PiS zwar gewählt haben, für die aber die Ideale des freien Polen der freien Bürger keineswegs an Aktualität verloren haben. Es ist nicht verwunderlich, dass die soziologischen Daten in der Form fortbestehen, wie sie zu Beginn des Regierungsantritts von PiS erhoben wurden. Die Regierung hat eine grundlegende Spaltung in der Gesellschaft herbeigeführt. Das Gefühl des Neids und der Wunsch, sich an allen zu rächen, die bisher erfolgreicher waren, höher aufgestiegen sind oder es besser verstanden haben, ihre Fähigkeiten zu nutzen, ist die Basis der Feindseligkeit der PiSAnhänger gegenüber der sogenannten Elite. Kaczyński ist es gelungen, ein hasserfülltes Bild von den "anderen« zu schaffen, die nicht seine Anhänger sind. Und wenn alle diese "anderen" unter eine Kategorie gefasst werden und ihnen zugeschrieben wird, dass sie privilegiert sind, dann ist man - obwohl das Ganze eine reine Erfindung ist - im Namen jener neiderfüllten »Gerechtigkeit« erfolgreich.

\section{Ausblick}

$\mathrm{Zu}$ guter Letzt sei auf die Reflexionen von Alexis de Tocqueville über die Demokratie und ihre Bedingungen verwiesen, die eine Bürgergesellschaft, wenn nicht gar eine Bürgernation gestalten. Erstens wird die Freiheit nicht nur von der tatsächlichen Ungleichheit, sondern auch vom Gefühl der Ungleichheit eines Teils der Bür- 
ger bed roht. Zweitens aber, insbesondere dann, wenn die Bürger die Politik als unmoralisch beurteilen und ihre egoistischen Interessen verfolgen, ermöglichen sie, dass eine Regierung entsteht, die im Namen der »Gleichheit" die Demokratie zerstört. Das polnische Beispiel zeigt, dass die Demokratie eine vergängliche Ordnung ist. Insbesondere dann, wenn die demokratischen Gepflo- genheiten nicht für einen ausreichend großen Teil der Bürger eine "Herzensangelegenheit» werden. Wenn das demokratische Ethos nicht der persönliche Wert des Bürgers wird, wird die Demokratie brüchig und kann sich unerwartet Diktatoren unterordnen.

Übersetzung aus dem Polnischen: Silke Plate

Über den Autor

Prof. Dr. Ireneusz Krzemiński, Soziologe, ist Professor am Institut für Soziologie der Universität Warschau (Instytut Socjologii, Uniwersytet Warszawski) und Leiter der Forschungsstelle zur Theorie des gesellschaftlichen Wandels. Seine Forschungsschwerpunkte sind Antisemitismus, Fremdenfeindlichkeit, nationale Stereotype und gesellschaftliche Minderheiten. Ein weiteres Forschungsgebiet ist die Solidarność als soziale Bewegung.

\section{Umfragen zu politischen Entwicklungen}

Grafik 1: Entwickelt sich die Situation in unserem Land in eine gute oder in eine schlechte Richtung?

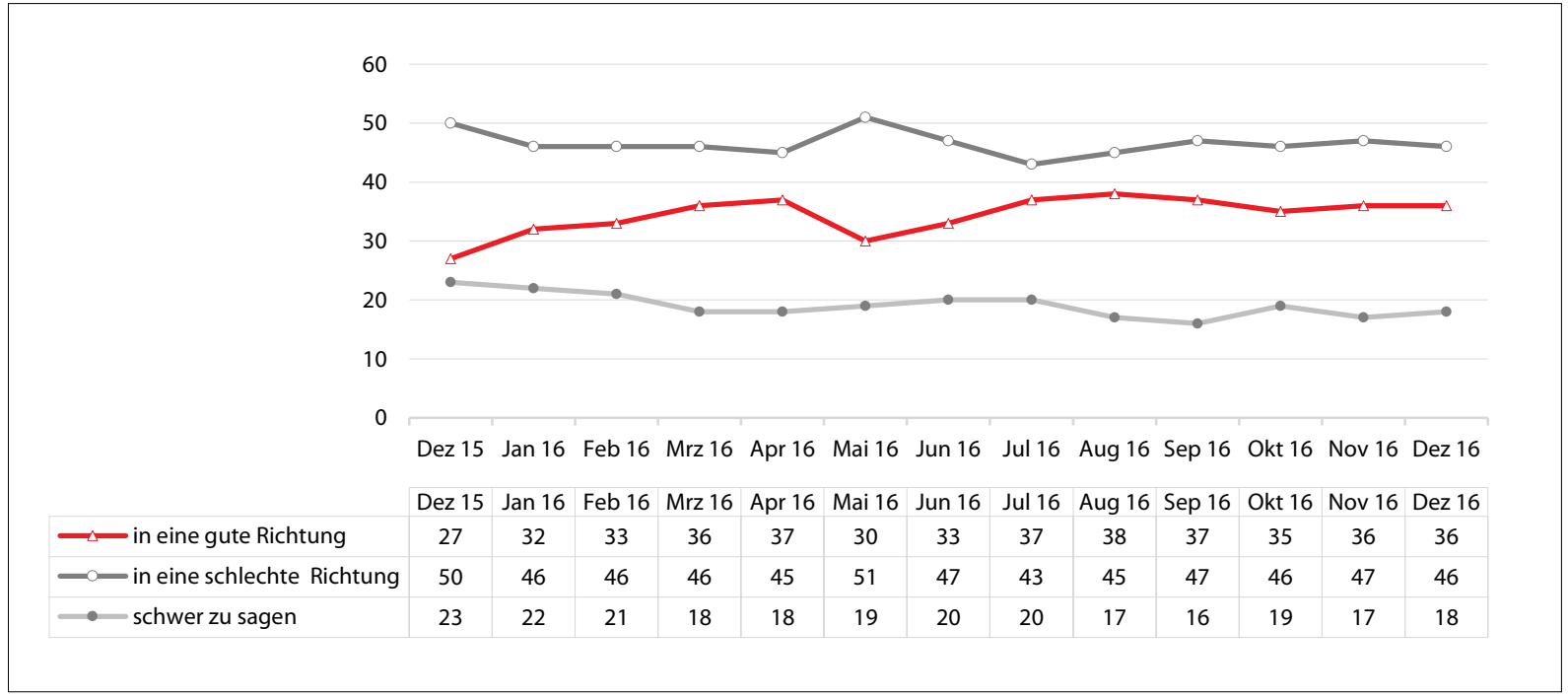

Quelle: CBOS Komunikat z Badań Nr 174/2016: Nastroje społeczne w grudniu [Die Stimmungen in der Gesellschaft im Dezember]. Warszawa 12/2016. <www.cbos.pl> 
Grafik 2: Entwickelt sich die Situation in unserem Land in eine gute oder in eine schlechte Richtung?

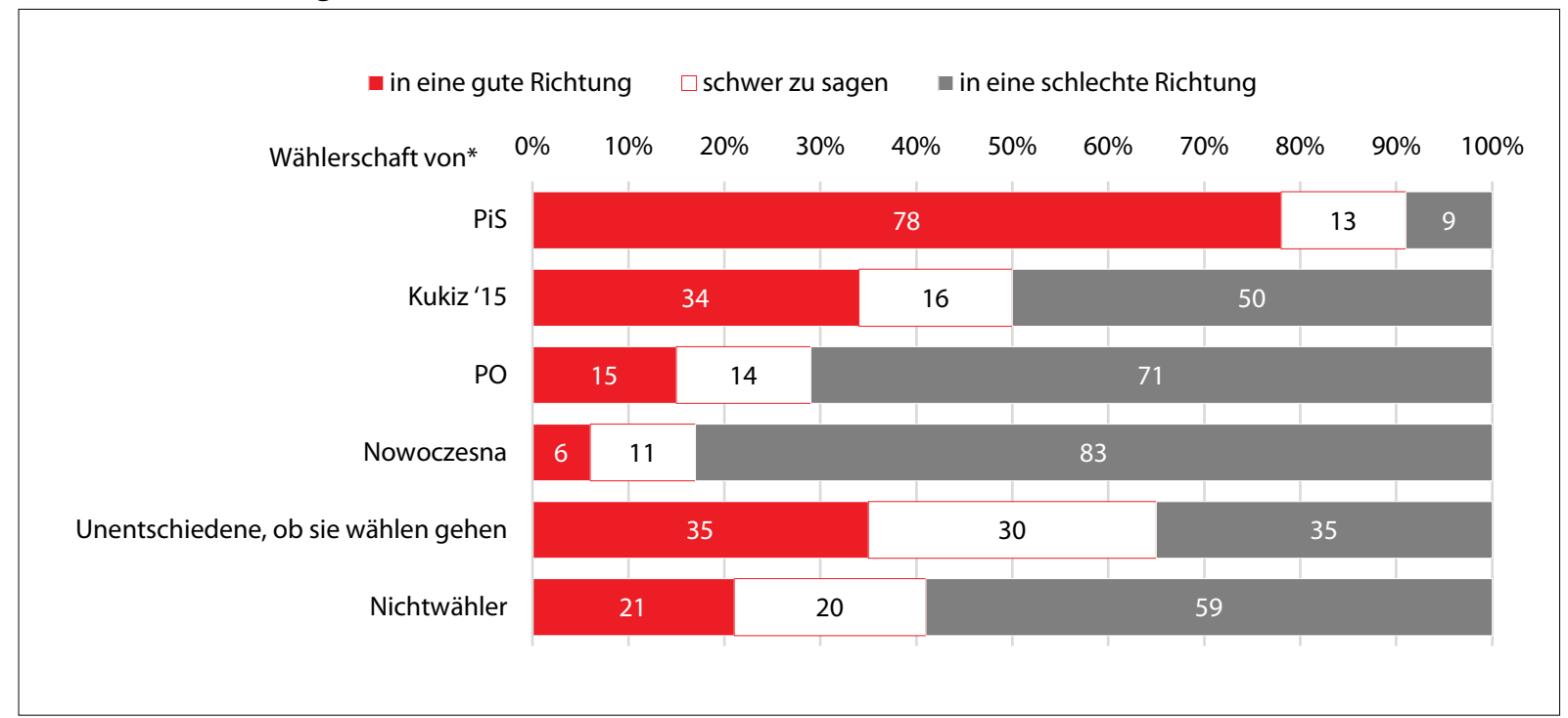

* deklarierte Teilnahme an potentiellen Parlamentswablen

PiS - Prawo i Sprawiedliwość/Recht und Gerechtigkeit; PO - Platforma Obywatelska/Bürgerplattform; Nowoczesna/Die Moderne Quelle: CBOS Komunikat z Badań Nr 174/2016: Nastroje społeczne w grudniu [Die Stimmungen in der Gesellschaft im Dezember]. Warszawa 12/2016. <www.cbos.pl>

\section{Grafik 3: Die Einstellung zur Regierung (\%)}

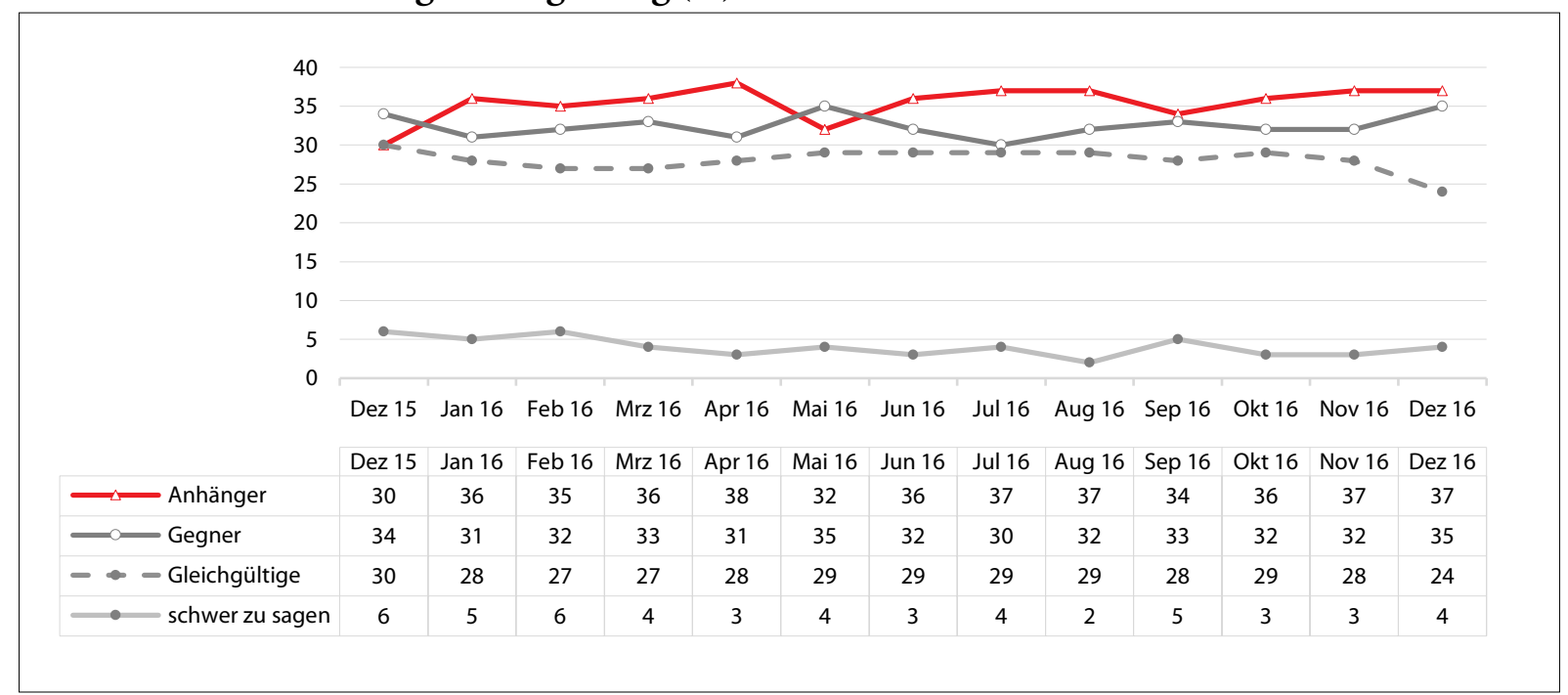

Quelle: CBOS Komunikat z Badań Nr 173/2016: Stosunek do rządu w grudniu [Die Einstellung zur Regierung im Dezember]. Warszawa 12/2016. <www.cbos.pl> 
Grafik 4: Sind Sie damit zufrieden, dass Beata Szydło Ministerpräsidentin ist? (\%)

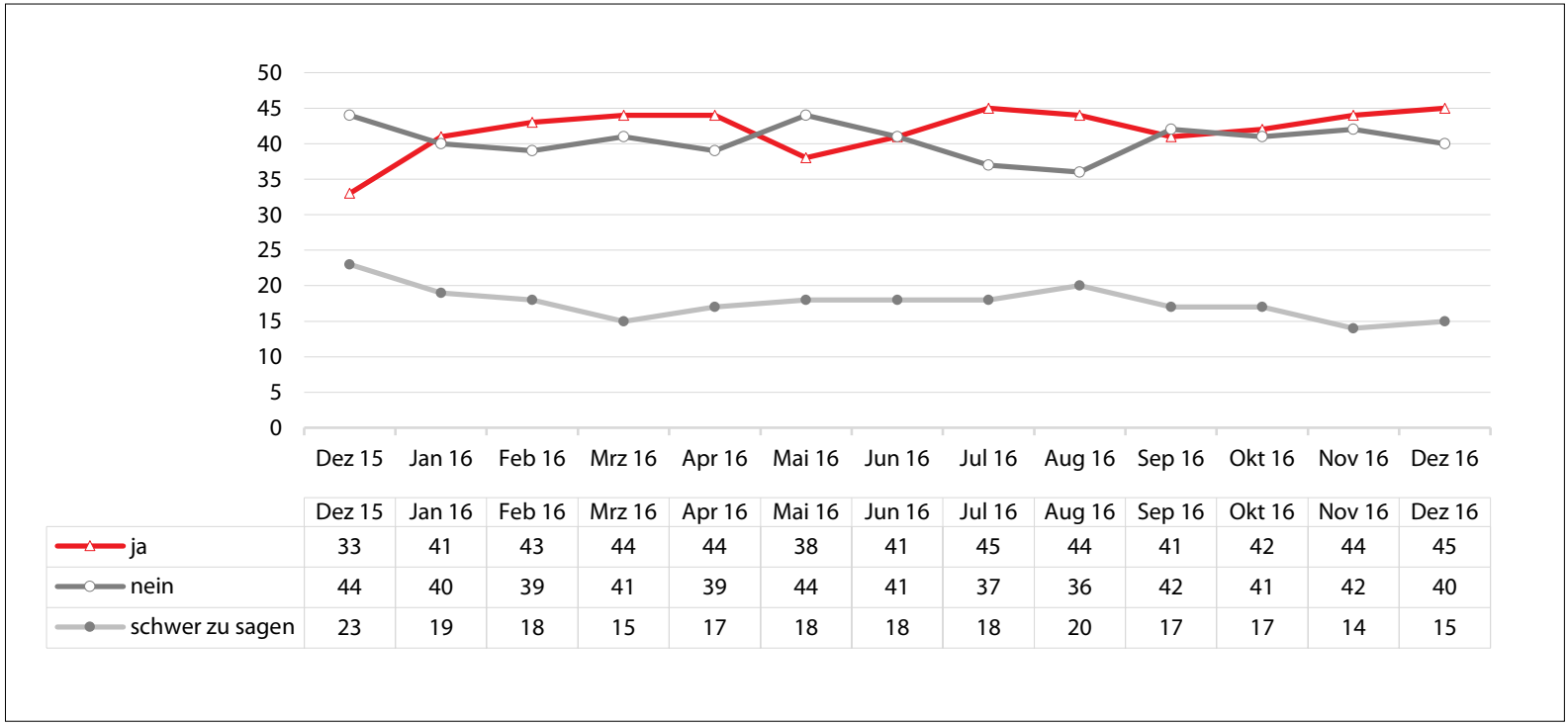

Quelle: CBOS Komunikat z Badań Nr 173/2016: Stosunek do rządu w grudniu [Die Einstellung zur Regierung im Dezember]. Warszawa 12/2016. <www.cbos.pl>

Grafik 5: Eröffnet die Politik der aktuellen Regierung die Chance auf eine Verbesserung der wirtschaftlichen Situation? (\%)

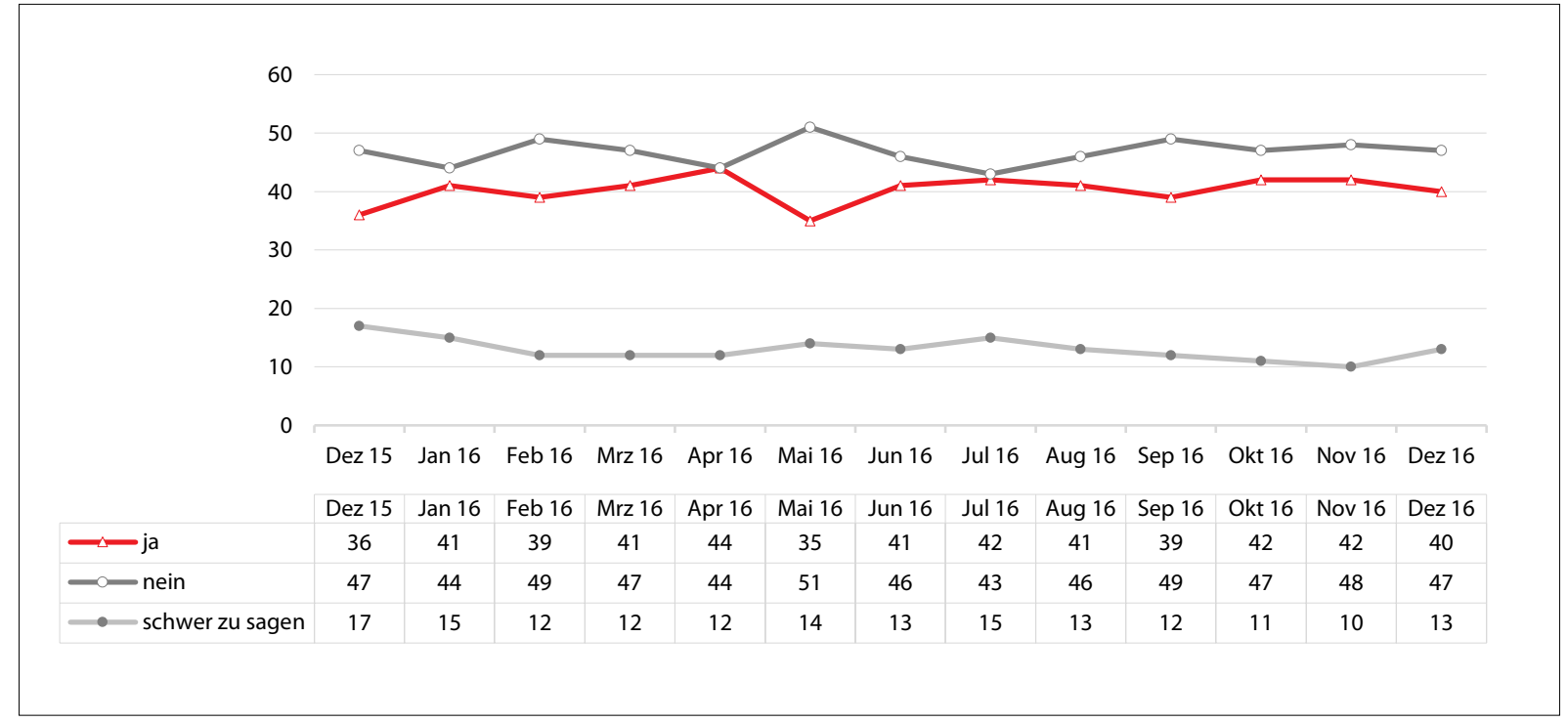

Quelle: CBOS Komunikat z Badań Nr 173/2016: Stosunek do rządu w grudniu [Die Einstellung zur Regierung im Dezember]. Warszawa 12/2016. <www.cbos.pl> 
Grafik 6: Welche Partei würden Sie wählen, wenn am kommenden Sonntag Parlamentswahlen wären? (\%)

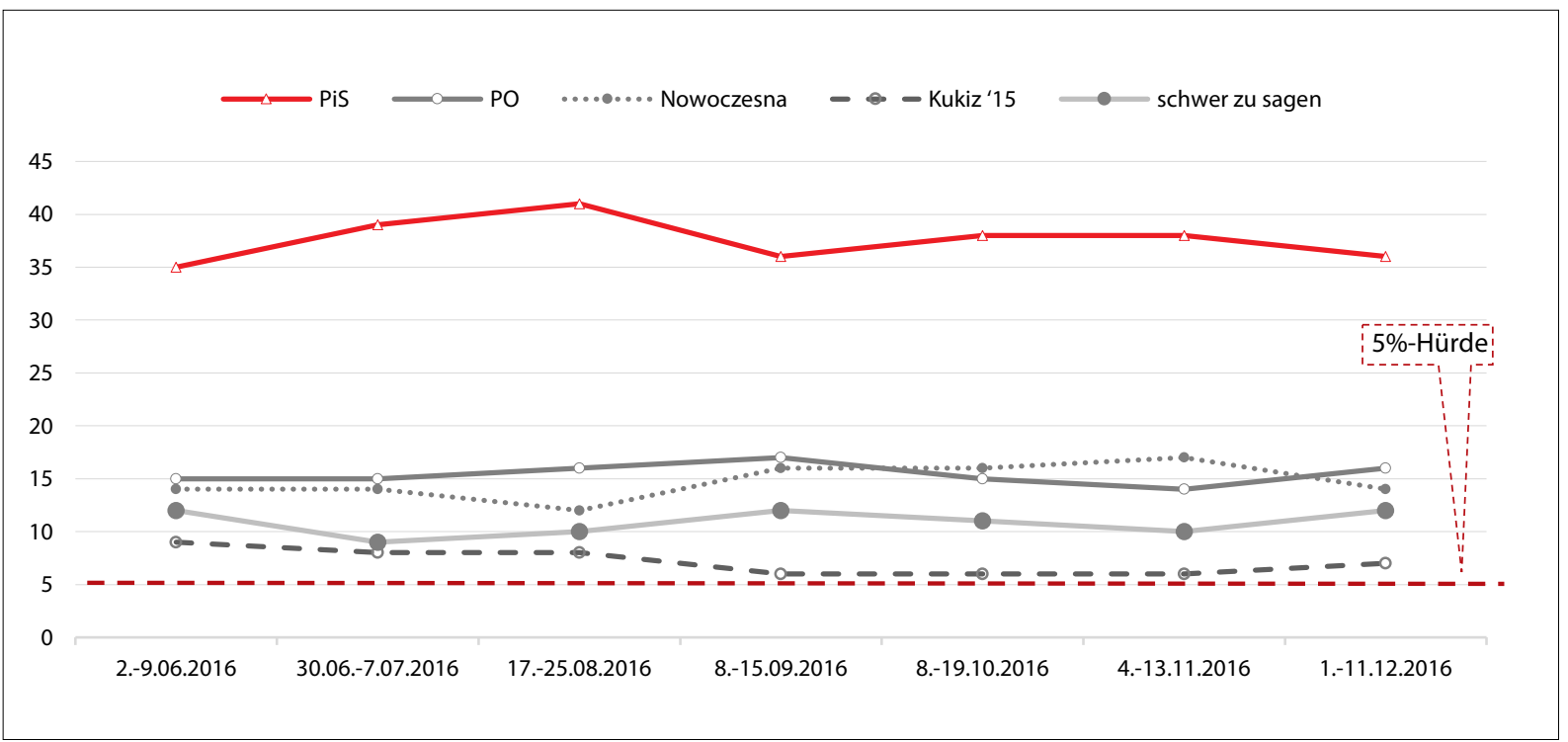

PiS - Prawo i Sprawiedliwość/Recht und Gerechtigkeit; PO - Platforma Obywatelska/Bürgerplattform; Nowoczesna/Die Moderne; SLD - Sojusz Lewicy Demokratycznej/Demokratische Linksallianz; PSL - Polskie Stronnictwo Ludowe/Polnische Bauernpartei;

Quelle: CBOS Komunikat z Badań Nr 170/2016: Preferencje partyjne w grudniu [Parteipräferenzen im Dezember]. Warszawa 12/2016. $<$ www.cbos.pl>

Tabelle 1: Welche Partei würden Sie wählen, wenn am kommenden Sonntag Parlamentswahlen wären? (\%)

\begin{tabular}{|c|c|c|c|c|c|c|c|c|}
\hline & 产 & $\begin{array}{l}\text { No } \\
1 \\
\dot{O} \\
\dot{i} \\
0 \\
0\end{array}$ & 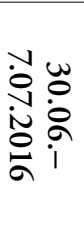 & 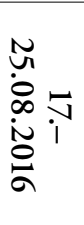 & $\begin{array}{l}\infty \\
\dot{1} \\
\stackrel{1}{1} \\
\dot{0} \\
\dot{0} \\
\dot{0} \\
0\end{array}$ & $\begin{array}{l}\infty \\
i \\
i \\
\dot{1} \\
\dot{0} \\
\dot{0} \\
0 \\
a\end{array}$ & 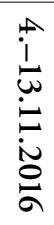 & 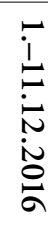 \\
\hline PiS & 37,58 & 35 & 39 & 41 & 36 & 38 & 38 & 36 \\
\hline $\mathrm{PO}$ & 24,09 & 15 & 15 & 16 & 17 & 15 & 14 & 16 \\
\hline Nowoczesna & 7,60 & 14 & 14 & 12 & 16 & 16 & 17 & 14 \\
\hline Kukiz '15 & 8,81 & 9 & 8 & 8 & 6 & 6 & 6 & 7 \\
\hline SLD & $7,55^{*}$ & 5 & 3 & 3 & 3 & 4 & 5 & 4 \\
\hline PSL & 5,13 & 2 & 3 & 3 & 3 & 4 & 4 & 3 \\
\hline $\begin{array}{l}\text { "Wolność«" } \\
\text { (KORWiN) }\end{array}$ & 4,76 & 3 & 4 & 2 & 2 & 3 & 2 & 3 \\
\hline Partia Razem & 3,62 & 3 & 3 & 3 & 2 & 2 & 1 & 2 \\
\hline andere Antwort & 0,87 & 1 & 1 & 1 & 2 & $<1$ & 2 & 2 \\
\hline $\begin{array}{l}\text { schwer zu } \\
\text { sagen }\end{array}$ & & 12 & 9 & 10 & 12 & 11 & 10 & 12 \\
\hline keine Antwort & & 0 & 1 & 1 & $<1$ & $<1$ & $<1$ & 1 \\
\hline
\end{tabular}

PiS - Prawo i Sprawiedliwość/Recht und Gerechtigkeit; PO - Platforma Obywatelska/Bürgerplattform; Nowoczesna/Die Moderne; SLD - Sojusz Lewicy Demokratycznej/Demokratische Linksallianz; PSL - Polskie Stronnictwo Ludowe/Polnische Bauernpartei; "Wolnośc" (KORWiN)/"Freiheit" (KORWiN); Partia Razem/Partei Gemeinsam

Quelle: CBOS Komunikat z Badań Nr 170/2016: Preferencje partyjne w grudniu [Parteipräferenzen im Dezember]. Warszawa 12/2016. $<$ www.cbos.pl> 
Tabelle 2: Vertrauen gegenüber Politikern (\%)

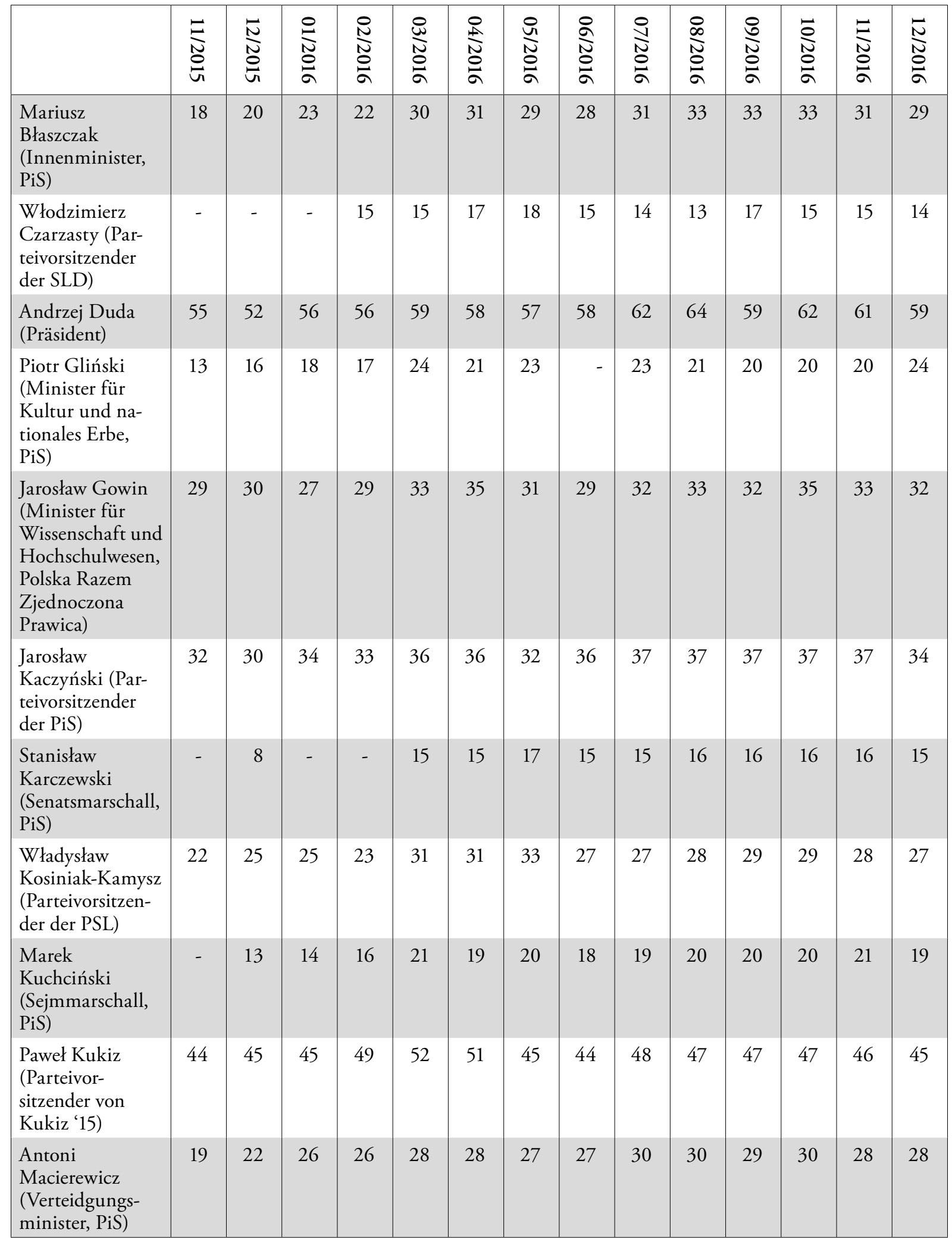


Tabelle 2: Vertrauen gegenüber Politikern (\%) (Fortsetzung)

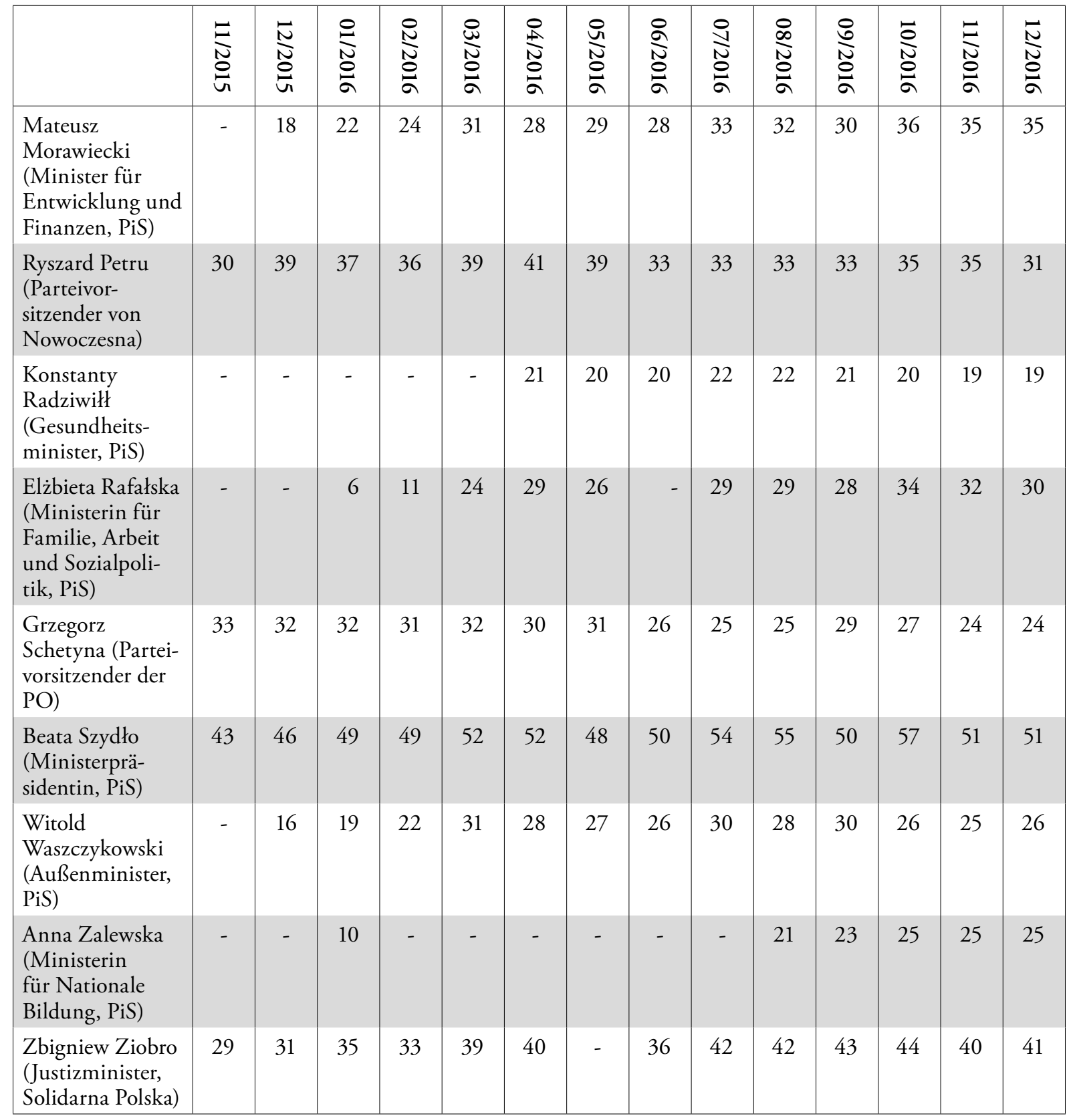

PiS-Prawo i Sprawiedliwość/Recht und Gerechtigkeit; SLD - Sojusz Lewicy Demokratyzcnej/Demokratische Linksallianz; Polska Razem Zjednoczona Prawica/Polen Gemeinsam Vereinigte Rechte; PSL - Polskie Stronnictwo Ludowe/Polnische Bauernpartei; Nowoczesnal Die Moderne; PO - Platforma Obywatelska/Bürgerplattform, Solidarna Polska/Solidarisches Polen

Quelle: CBOS Komunikat z Badań Nr 176/2016: Zaufanie do polityków w grudniu [Vertrauen gegenüber Politikern im Dezember]. Warszawa 12/2016. <www.cbos.pl> 
Tabelle 3: Welchem polnischen Politiker gebührt Ihrer Meinung nach die Bezeichnung»Politiker des Jahres 2016«? (\%)

\begin{tabular}{|l|c|}
\hline Andrzej Duda [Präsident der Republik Polen] & 12 \\
Beata Szydło [Ministerpräsidentin] & 8 \\
\hline Jarosław Kaczyński [Parteivorsitzender der PiS] & 4 \\
\hline Donald Tusk [Präsident des Europäischen Rates, PO] & 3 \\
Mateusz Morawiecki [Minister für Entwicklung und Finanzen, PiS] & 2 \\
\hline Paweł Kukiz [Parteivorsitzender von Kukiz '15] & 1 \\
Ryszard Petru [Parteivorsitzender von Nowoczesna] & 1 \\
\hline Zbigniew Ziobro [Justizminister, Parteivorsitzender von Solidarna Polska] & 1 \\
Władysław Kosiniak-Kamysz [Parteivorsitzender der PSL] & 1 \\
\hline Andrzej Rzepliński [Präsident des Verfassungstribunals] & 1 \\
Aleksander Kwaśniewski [Präsident der Republik Polen 1995-2005] & 1 \\
\hline Lech Wałęsa [Präsident der Republik Polen 1990-1995] & 1 \\
andere Politiker (42 Namen), insgesamt & 6 \\
\hline Es gibt niemanden, niemand hat sich besonders verdient gemacht. & 26 \\
\hline Ich weiß nicht; es interessiert mich nicht; schwer zu sagen. & 32 \\
\hline
\end{tabular}

PiS - Prawo i Sprawiedliwość/Recht und Gerechtigkeit; PO - Platforma Obywatelska/Bürgerplattform; Nowoczesna/Die Moderne; Solidarna Polska/Solidarisches Polen; PSL - Polskie Stronnictwo Ludowe/Polnische Bauernpartei

Quelle: CBOS Komunikat z Badań Nr 2/2017: Polityk roku 2016 w Polsce i na świecie [Der Politiker des Jahres in Polen und in der Welt]. Warszawa 01/2017. <www.cbos.pl> 


\section{Dezember 2016 - 16. Januar 2017}

\begin{tabular}{|c|c|}
\hline 06.12 .2016 & $\begin{array}{l}\text { Der "Berliner Tagesspiegel« berichtet über die Entlassung der Direktorin des Polnischen Kulturinstituts in Ber- } \\
\text { lin, Katarzyna Wielga-Skolimowska, die ohne Vorankündigung und Nennung von Gründen vollzogen wurde. } \\
\text { Internen Informationen zufolge wird der Direktorin vorgeworfen, jüdische Themen zu stark zu behandeln. Auch } \\
\text { solle vermieden werden, dass Deutschland die Rolle eines Vermittlers im polnisch-jüdischen Dialog erhalte. In } \\
\text { einem offenen Brief an Außenminister Witold Waszczykowski und den Botschafter der Republik Polen, Andrzej } \\
\text { Przylebski, protestieren namhafte Vertreter der Kulturszene in Deutschland gegen die Entlassung. }\end{array}$ \\
\hline 07.12 .2016 & $\begin{array}{l}\text { Donald Tusk, Präsident des Europäischen Rates und ehemaliger Ministerpräsident Polens, kritisiert im Interview } \\
\text { für das Portal Onet.pl, dass die Außenpolitik der Regierung von Recht und Gerechtigkeit (Prawo i Sprawiedli- } \\
\text { wość-PiS) zur Marginalisierung Polens in Europa führe. Die Regierung versäume, die Beziehungen zu Deutsch- } \\
\text { land und Frankreich zu stärken und größeren Einfluss in Europa zu gewinnen, Polen trage jedoch Mitverantwor- } \\
\text { tung für die Einheit Europas. Er selbst engagiere sich für gute Beziehungen zu Deutschland und Frankreich im } \\
\text { Rahmen seiner Präsidentschaft. }\end{array}$ \\
\hline 08.12 .2016 & $\begin{array}{l}\text { Der ungarische Ministerpräsident Viktor Orbán kommt zu einem informellen zweitägigen Besuch nach Krakau } \\
\text { (Kraków). In einem Gespräch mit Ministerpräsidentin Beata Szydło werden Fragen der europäischen Migrati- } \\
\text { ons- und Asylpolitik als Vorbereitung auf den EU-Gipfel in der kommenden Woche thematisiert. Des Weite- } \\
\text { ren trifft sich Orbán mit dem Parteivorsitzenden von Recht und Gerechtigkeit (Prawo i Sprawiedliwość - PiS), } \\
\text { Jarosław Kaczyński. }\end{array}$ \\
\hline 09.12 .2016 & $\begin{array}{l}\text { Bei ihrem Besuch in der albanischen Hauptstadt Tirana sagt Ministerpräsidentin Beata Szydło Albanien die Unter- } \\
\text { stützung Polens bei seinen Bemühungen um die Mitgliedschaft in der EU zu. }\end{array}$ \\
\hline 12.12 .2016 & $\begin{array}{l}\text { Außenminister Witold Waszczykowski kritisiert die Entscheidung des Präsidiums des Europäischen Parlamen- } \\
\text { tes, am 13. Dezember erneut eine Debatte zum Thema Rechtsstaatlichkeit in Polen zu führen. Es gebe nichts } \\
\text { zu diskutieren, weil Polen kein Problem darstelle, die EU habe aber andere Probleme. Die Wahl des Termins sei } \\
\text { unglücklich, da dies der Tag der Verhängung des Kriegsrechts (1981), eines antidemokratischen Aktes gegenüber } \\
\text { Polen, gewesen sei. }\end{array}$ \\
\hline 13.12 .2016 & $\begin{array}{l}\text { Der Sejm verabschiedet das dritte Gesetz des Pakets zur Neuordnung des Verfassungstribunals. Es erklärt die } \\
\text { Wahl der Kandidaten für den Vorsitz des Verfassungstribunals für ungültig, die die Allgemeine Versammlung } \\
\text { des Verfassungstribunals Ende November durchgeführt hat, da die Amtszeit des aktuellen Präsidenten des Tri- } \\
\text { bunals, Andrzej Rzepliński, in wenigen Tagen endet. Nach neuer Gesetzeslage wird ein Interimspräsident bis zur } \\
\text { Berufung eines neuen Präsidenten des Gerichts eingesetzt. }\end{array}$ \\
\hline 13.12 .2016 & $\begin{array}{l}\text { In zahlreichen Städten nehmen Tausende an Gedenkmärschen anlässlich des 35. Jahrestages der Verhängung des } \\
\text { Kriegsrechts in der Volksrepublik Polen statt. Die Hauptorganisationen kommen aus dem Lager der Regierungs- } \\
\text { partei Recht und Gerechtigkeit (Prawo i Sprawiedliwość - PiS) bzw. des Komitees zur Verteidigung der Demo- } \\
\text { kratie (Komitet Obrony Demokracji - KOD). }\end{array}$ \\
\hline 14.12 .2016 & $\begin{array}{l}\text { Der Sejm verabschiedet das Gesetz über die Schulreform. Ab dem 1. September } 2017 \text { wird die Schulform der } \\
\text { Mittelschule ("gimnazjum«) abgeschafft. Die Schulausbildung kehrt zum ehemaligen System zurück: acht Jahre } \\
\text { Grundschule, vier Jahre Oberschule; fünf Jahre Technikum sowie eine zweistufige Berufsschule. Für die Reform } \\
\text { stimmten } 230 \text { Abgeordnete, } 199 \text { stimmten dagegen, fünf enthielten sich. }\end{array}$ \\
\hline 16.12 .2016 & $\begin{array}{l}\text { Im Plenarsaal des Sejm blockieren Politiker der Opposition das Rednerpult als Reaktion auf das Vorhaben der } \\
\text { Regierung, die Arbeit von Medienvertretern im Parlament einzuschränken, sowie auf die Entscheidung von } \\
\text { Sejmmarschall Marek Kuchciński, den Abgeordneten der Bürgerplattform (Platforma Obywatelska-PO) Michał } \\
\text { Szczerba von der Sitzung auszuschließen. Vor dem Sejm findet eine Demonstration für den uneingeschränkten } \\
\text { Zugang der Medien zum Parlament sowie zur Unterstützung der protestierenden Parlamentarier im Sejm statt. }\end{array}$ \\
\hline 16.12 .2016 & $\begin{array}{l}\text { Wegen der Blockade des Rednerpults im Plenarsaal des Sejm durch Oppositionspolitiker findet die Abstimmung } \\
\text { über das Haushaltsgesetz } 2017 \text { im »Säulensaal« des Parlamentsgebäudes in Abwesenheit von Oppositionsabge- } \\
\text { ordneten statt. }\end{array}$ \\
\hline 16.12 .2016 & $\begin{array}{l}\text { Abgeordnete von Bürgerplattform (Platforma Obywatelska - PO) und Die Moderne (Nowoczesna) bleiben bis } \\
\text { auf Weiteres im Plenarsaal des Sejm. Sie protestieren damit gegen den Ausschluss des PO-Abgeordneten Michał } \\
\text { Szczerba von der Parlamentssitzung und gegen das Vorhaben der Regierung, die Arbeit der Medienvertreter im } \\
\text { Parlamentsgebäude einzuschränken. }\end{array}$ \\
\hline 17.12 .2016 & $\begin{array}{l}\text { In der Nacht vom 16. auf den 17. Dezember blockieren Demonstranten das Parlamentsgebäude und verhindern, } \\
\text { dass Politiker den Sejm verlassen. Die Polizei löst die Blockade auf. }\end{array}$ \\
\hline
\end{tabular}




\begin{tabular}{|c|c|}
\hline 18.12 .2016 & $\begin{array}{l}\text { In Krakau (Kraków) blockiert eine Gruppe von Demonstranten die Zufahrt zum Wawel für Politiker der Regie- } \\
\text { rungspartei Recht und Gerechtigkeit (Prawo i Sprawiedliwość - PiS), darunter auch für den Parteivorsitzenden } \\
\text { Jarosław Kaczyński und Ministerpräsidentin Beata Szydło. Die Polizei löst die Blockade auf. Kaczyński besucht } \\
\text { am 18. eines jeden Monats das Grab seines beim Flugzeugabsturz von Smolensk (2010) tödlich verunglückten } \\
\text { Bruders, der auf dem Wawel am 18. April } 2010 \text { beigesetzt wurde. }\end{array}$ \\
\hline 19.12 .2016 & $\begin{array}{l}\text { Präsident Andrzej Duda richtet einen Brief an Sejmmarschall Marek Kuchciński (Recht und Gerechtigkeit/Prawo } \\
\text { i Sprawiedliwość - PiS), in dem er nach den Umständen der Abstimmung des Haushaltsgesetzes am 16. Dezem- } \\
\text { ber fragt. Die Abstimmung wurde aus dem Parlamentssaal in einen anderen Saal verlegt, da Oppositionspolitiker } \\
\text { das Rednerpult blockierten. Die Opposition zweifelt die Rechtmäßigkeit der Abstimmung an. Im Rahmen der } \\
\text { Mediation des Konflikts zwischen der Regierungspartei und den Oppositionsparteien sucht Duda das Gespräch } \\
\text { mit beiden Seiten. }\end{array}$ \\
\hline 20.1 & $\begin{array}{l}\text { Nach dem mutmaßlichen Terroranschlag mit einem LKW auf einen Weihnachtsmarkt in Berlin am Vorabend } \\
\text { unterstreicht Ministerpräsidentin Beata Szydło, dass Europa vereint gegen den Terrorismus kämpfen und seine } \\
\text { Bürger schützen muss. Der Familie des tot in der Fahrerkabine des LKW aufgefundenen polnischen LKW-Fah- } \\
\text { rers Łukasz Urban drückt Szydło ihr Mitgefühl aus. Er sei das erste Todesopfer des schändlichen Gewaltaktes. }\end{array}$ \\
\hline 21.12 & $\begin{array}{l}\text { Die EU-Kommission setzt Polen erneut eine Frist von zwei Monaten, um Änderungen an der Reform des Verfas- } \\
\text { sungstribunals vorzunehmen, da eine Beschränkung der Kontrollfunktion des Verfassungstribunals zu befürch- } \\
\text { ten sei. }\end{array}$ \\
\hline 21.1 & $\begin{array}{l}\text { Die Verfassungsrichterin Julia Przyłębska wird von Präsident A } \\
\text { als Nachfolgerin von Andrzej Rzepliński ernannt. Die Ernenn }\end{array}$ \\
\hline 24.12 & $\begin{array}{l}\text { Das Verteidigungsministerium teilt mit, dass Polen von den USA Marschflugkörper des Typs JASSM Extended } \\
\text { Range mit einer Reichweite von knapp } 1.000 \mathrm{~km} \text { kaufen wird. Der Vertrag in Höhe von ca. } 940 \text { Mio. Zloty } \\
\text { wurde unterzeichnet. }\end{array}$ \\
\hline 28.1 & $\begin{array}{l}\text { Der Parteivorsitzende von Die Moderne (Nowoczesna), Ryszard Petru, erklärt nach einer Sitzung des Parteivor- } \\
\text { stands, dass seine Partei die Blockade des Plenarsaals im Sejm bis zum 11. Januar } 2017 \text { aufrechterhalten wird. An } \\
\text { diesem Tag soll regulär die nächste Parlamentssitzung stattfinden. Er erklärt sich zu einem Gespräch mit Jarosław } \\
\text { Kaczyński, Parteichef von Recht und Gerechtigkeit (Prawo i Sprawiedliwość - PiS), über einen Ausweg aus der } \\
\text { „Sejmkrise«, die am 16. Dezember begonnen hat, bereit. }\end{array}$ \\
\hline 29.1 & $\begin{array}{l}\text { Ministerpräsidentin Beata Szydło teilt mit, dass sich die Regierung und die Fraktion von Recht und Gerechtig- } \\
\text { keit (Prawo i Sprawiedliwość - PiS) durch die Proteste der Opposition im Plenarsaal des Sejm nicht von ihrem } \\
\text { Programm und ihrem Zeitplan abbringen lassen. Die Verabschiedung des Haushaltsgesetzes am 16. Dezember } \\
\text { sei verfassungskonform gewesen; die Opposition müsse sich fragen lassen, wessen Interessen sie vertrete, wenn } \\
\text { sie sich, statt sich um ihre Pflichten als Abgeordnete zu kümmern und für die Bevölkerung zu arbeiten, mit sich } \\
\text { selbst beschäftige. }\end{array}$ \\
\hline 29.12 & $\begin{array}{l}\text { Das Kabinett beschließt einen Gesetzeser } \\
\text { kehr, mit dem die betreffenden EU-Vorsc }\end{array}$ \\
\hline 30.1 & $\begin{array}{l}\text { Nach neuesten Angaben der Polnischen Nationalbank (Narodowy Bank Polski - NBP) stieg im dritten Quartal } \\
2016 \text { die Auslandsverschuldung Polens brutto auf 315,14 Mrd. Euro. Der Warenexport stieg auf 42,6 Mrd. Euro, } \\
\text { der Import auf 43,3 Mrd. Euro. }\end{array}$ \\
\hline 31.12 & $\begin{array}{l}\text { In seiner Neujahrsansprache hebt Präsident Andrzej Duda hervor, dass Polen unter der von Recht und Gerechtig- } \\
\text { keit (Prawo i Sprawiedliwość - PiS) geführten Regierung solidarischer geworden sei, beispielsweise durch die Ein- } \\
\text { führung des Familienförderprogramms " } 500 \text { plus«, die Erhöhung des Mindestlohns und die Senkung des Renten- } \\
\text { eintrittsalters. Das Land sei sicherer geworden, da im kommenden Jahr die Vereinbarung des Warschauer NATO- } \\
\text { Gipfels umgesetzt werde und US-amerikanische Soldaten zur Verstärkung der NATO-Ostflanke in Polen sta- } \\
\text { tioniert würden. Im Interesse Polens lägen vor allem die Förderung der polnischen Wirtschaft und Innovationen } \\
\text { sowie eine stabile, geeinte und solidarische Europäische Union. }\end{array}$ \\
\hline 02.0 & $\begin{array}{l}\text { In der Sitzung des parlamentarischen Ausschusses für Energieangelegenheiten und Staatsschatz, in der die Restruk- } \\
\text { turierung der Kattowitzer Kohle Holding (Katowicki Holding Węglowy S.A.) beraten wird, unterstreicht Minis- } \\
\text { terpräsidentin Beata Szydło die Bedeutung des Bergbaus für eine gut entwickelte Wirtschaft. Das Klima für die } \\
\text { Modernisierung des polnischen Bergbaus sei aktuell günstig, da sie von den Verantwortlichen für diese Branche } \\
\text { in der Regierung entschieden unterstützt werde. }\end{array}$ \\
\hline 03.01.2017 & $\begin{array}{l}\text { Außenminister Witold Waszczykowski stellt dem Ministerrat die Außenpolitik Polens des vergangenen Jahres } \\
\text { sowie der kommenden zwölf Monate vor. Prioritär sind demnach } 2017 \text { u. a. die Sicherheit, eine starke Position } \\
\text { Polens in der EU und in Europa, die Integration Ostmitteleuropas und die Ostpolitik. }\end{array}$ \\
\hline
\end{tabular}




\begin{tabular}{|c|c|}
\hline 04.01 .2017 & $\begin{array}{l}\text { Senator Marek Borowski äußert sich in einem TV-Interview über die "Sejmkrise«, die seit der 33. Sitzung des Sejm } \\
\text { am 16. Dezember } 2016 \text { besteht. Der Ausschluss des Abgeordneten der Bürgerplattform (Platforma Obywatelska- } \\
\text { PO), Michał Szczerba, von der Debatte des Parlaments durch Sejmmarschall Marek Kuchciński sei nicht angemes- } \\
\text { sen und die Verlegung der Abstimmung über das Haushaltsgesetz in einen anderen Saal unprofessionell gewesen. } \\
\text { Es habe sich um eine Kräftemessen zwischen der regierenden Partei Recht und Gerechtigkeit (Prawo i Sprawie- } \\
\text { dliwość - PiS) und der Opposition gehandelt. Borowski fordert die Opposition auf, die Besetzung des Plenarsaals } \\
\text { des Parlaments zu beenden, erneut öffentlich bekannt zu geben, dass das Haushaltsgesetz nicht rechtskonform ver- } \\
\text { abschiedet wurde, und entsprechende Schritte einzuleiten, um Kuchciński dafür zur Verantwortung zu ziehen. }\end{array}$ \\
\hline 05.01 .2017 & $\begin{array}{l}\text { Aus dem Kriegshafen in Swinemünde (Świnoujście) läuft die »Kontradmiral Xawery Czernicki» der Polnischen } \\
\text { Marine zu einem halbjährigen Einsatz im Mittelmeer aus. Der Einsatz mit } 70 \text { Soldaten findet im Rahmen der } \\
\text { "Standing NATO Mine Counter Measures Group 2«statt. }\end{array}$ \\
\hline 06.01 .2017 & $\begin{array}{l}\text { Der Krakauer Kardinal Stanisław Dziwisz ruft in der Messe zum Feiertag der Heiligen Drei Könige zu Dialogbe- } \\
\text { reitschaft, gegenseitigem Respekt und Brüderlichkeit auf, um die Zivilisation des Guten aufzubauen. }\end{array}$ \\
\hline 07.01.2017 & $\begin{array}{l}\text { In Breslau (Wrocław) treffen die ersten } 250 \text { US-amerikanischen Soldaten der 3. Panzerbrigade der US-Armee ein, } \\
\text { die an verschiedenen Orten in Polen stationiert werden. Die USA verlegen im Rahmen der NATO-Operation } \\
\text { "Atlantic Resolve« eine komplette Panzerbrigade nach Ostmitteleuropa, wo sie zu Übungen in Polen, Litauen, } \\
\text { Lettland und Estland als Signal der Stärkung der Ostflanke der NATO eingesetzt werden. }\end{array}$ \\
\hline 09.0 & $\begin{array}{l}\text { An einem Gespräch auf Einladung von Senatsmarschall Stanisław Karczewski zur Klärung der sogenannten } \\
\text { Sejmkrise nehmen die Parteivorsitzenden Jarosław Kaczyński (Recht und Gerechtigkeit/Prawo i Sprawiedliwość- } \\
\text { PiS), Władysław Kosiniak-Kamysz (Polnische Bauernpartei/Polskie Stronnictwo Ludowe - PSL), Ryszard Petru } \\
\text { (Die Moderne/Nowoczesna), Paweł Kukiz (Kukiz '15), Zbigniew Ziobro (Solidarisches Polen/Solidarna Polska) } \\
\text { und Marek Zagórski (Polen Gemeinsam/Polska Razem) teil. Grzegorz Schetyna, Chef der Bürgerplattform (Plat- } \\
\text { forma Obywatelska - PO), begründete seine Abwesenheit damit, dass die Lösung der Krise nicht vom Senatsmar- } \\
\text { schall, sondern vom Sejmmarschall betrieben werden müsse. Nach dem Gespräch teilt Kaczyński mit, dass der } \\
\text { Umgang mit der strittigen Abstimmung über das Haushaltsgesetz am 16. Dezember } 2016 \text { offen geblieben sei und } \\
\text { die Anwesenden zugesagt hätten, dass ihre Fraktionen nicht mehr das Rednerpult im Parlament blockieren würden. }\end{array}$ \\
\hline 09.0 & $\begin{array}{l}\text { Ryszard Petru, Parteivorsitzender von Die Moderne (Nowoczesna), sagt nach dem Gespräch der Parteichefs zur } \\
\text { Lösung der »Sejmkrise«, seine Partei halte die Abstimmung über das Haushaltsgesetz für das Jahr } 2017 \text { am } 16 . \\
\text { Dezember } 2016 \text { weiter für illegal. Es liege im Interesse Polens, des Parlaments und der Regierungspartei Recht } \\
\text { und Gerechtigkeit (Prawo i Sprawiedliwość - PiS), über den Haushalt für das Jahr } 2017 \text { legal abzustimmen, damit } \\
\text { er nicht fortwährend in Frage gestellt werden wird. }\end{array}$ \\
\hline 10.0 & $\begin{array}{l}\text { Nach einem weiteren Treffen der Parteivorsitzenden zur Lösung der »Sejmkrise« spricht sich Parteichef Ryszard } \\
\text { Petru (Die Moderne/Nowoczesna) für ein Gespräch mit den Vorsitzenden der Oppositionsparteien Grzegorz } \\
\text { Schetyna (Bürgerplattform (Platforma Obywatelska - PO) und Władysław Kosiniak-Kamysz (Polnische Bauern- } \\
\text { partei/Polskie Stronnictwo Ludowe-PSL) aus, um die Möglichkeit eines Antrags aufVerkürzung der Amtszeit des } \\
\text { Parlaments zu diskutieren. Schetyna hat wie am Vortag auch an dem heutige Krisentreffen nicht teilgenommen. }\end{array}$ \\
\hline 11.0 & $\begin{array}{l}\text { Nach Aussagen des Fraktionsvorsitzenden der Bürgerplattform (Platforma Obywatelska-PO), Sławomir Neumann, } \\
\text { erwartet die PO, dass Sejmmarschall Marek Kuchciński (Recht und Gerechtigkeit/Prawo i Sprawiedliwość - PiS) } \\
\text { die 33. Sitzung des Sejm vom 16. Dezember } 2016 \text { am heutigen Sitzungstag des Sejm wieder aufnimmt, da diese } \\
\text { damals nicht beendet, sondern nur aufgehoben worden sei. Andernfalls würde die PO die Blockade des Redner- } \\
\text { pults im Plenarsaal des Sejm fortsetzen. }\end{array}$ \\
\hline 11.01 & $\begin{array}{l}\text { Sejmmarschall Marek Kuchciński (Recht und Gerechtigkeit/Prawo i Sprawiedliwość - PiS) eröffnet die 34. Sit- } \\
\text { zung des Sejm, die anschließend auf den kommenden Tag vertagt wird. Sławomir Neumann, Fraktionschef der } \\
\text { Bürgerplattform (Platforma Obywatelska - PO), kündigt an, dass Abgeordnete der PO bis zum nächsten Tag } \\
\text { im Plenarsaal bleiben werden. Die Besetzung des Plenarsaals dauert seit dem 16. Dezember 2016, als die soge- } \\
\text { nannte Sejmkrise begann. }\end{array}$ \\
\hline 12.01 .2017 & $\begin{array}{l}\text { Grzegorz Schetyna, Parteivorsitzender der Bürgerplattform (Platforma Obywatelska - PO), gibt die Aussetzung } \\
\text { der Blockade des Plenarsaals im Parlamentsgebäude bekannt. Diese dauerte seit dem 16. Dezember 2016. Die PO } \\
\text { sei bereits, die Proteste wieder aufzunehmen, sollte die Regierungspartei Recht und Gerechtigkeit (Prawo i Spra- } \\
\text { wiedliwość - PiS) weiter widerrechtlich agieren. }\end{array}$ \\
\hline 12.01 .2017 & Sejmmarschall Marek Kuchciński ordnet eine Pause der 34. Sejmsitzung bis zum 25. Januar an. \\
\hline 13.01 .2017 & $\begin{array}{l}\text { Präsident Andrzej Duda unterzeichnet das Haushaltsgesetz 2017, über das der Sejm am 16. Dezember } 2016 \text { abge- } \\
\text { stimmt hat. Der Konflikt um das Haushaltsgesetz ist Gegenstand der sogenannten Sejmkrise, die damalige Abstim- } \\
\text { mung stuft die Opposition als rechtswidrig ein. }\end{array}$ \\
\hline
\end{tabular}




\begin{tabular}{|l|l|}
\hline 15.01.2017 & $\begin{array}{l}\text { Der Parteivorsitzende von Recht und Gerechtigkeit (Prawo i Sprawiedliwość - PiS), Jarosław Kaczyński, kündigt } \\
\text { bei einem Treffen mit PiS-Mitgliedern in Danzig (Gdańsk) an, dass PiS vor den Selbstverwaltungswahlen } 2018 \\
\text { eine Änderung des Wahlrechts anstrebt. U. a. soll die Amtszeit von Woiwoden, Bürgermeistern und Stadtpräsi- } \\
\text { denten auf maximal zwei Wahlperioden beschränkt werden. }\end{array}$ \\
\hline 16.01 .2017 & $\begin{array}{l}\text { Der Parteivorsitzende von Recht und Gerechtigkeit (Prawo i Sprawiedliwość - PiS), Jarosław Kaczyński, behaup- } \\
\text { tet in einem Radiointerview, dass die Opposition in der »Sejmkrise« der vergangenen Wochen verfassungswid- } \\
\text { rig und gegen die Regularien des Sejm und der Abgeordneten sowie des Strafgesetzbuches gehandelt habe. Dem } \\
\text { Antrag auf Abberufung von Sejmmarschall Marek Kuchciński (PiS), den die Bürgerplattform (Platforma Oby- } \\
\text { watelska - PO) gestellt hat, erteilt Kaczyński eine Absage. }\end{array}$ \\
\hline
\end{tabular}

Sie können die gesamte Chronik seit 2007 auch auf <http://www.laender-analysen.de/polen/> unter dem Link "Chronik«lesen. 


\section{ÜBER DIE POLEN-ANALYSEN}

Die Polen-Analysen erscheinen zweimal monatlich als E-Mail-Dienst. Sie werden gemeinsam vom Deutschen PolenInstitut Darmstadt, der Forschungsstelle Osteuropa an der Universität Bremen und der Deutschen Gesellschaft für Osteuropakunde herausgegeben.

Ein Archiv der Polen-Analysen finden Sie im Internet unter <www.laender-analysen.de/polen>

Kostenloses Abonnement unter <http://www.deutsches-polen-institut.de/Newsletter/subscribe.php>

Diese Analysen finden Sie online als Lizenzausgabe auf

$<$ bpb.de>

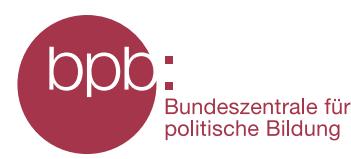

Deutsches Polen-Institut Darmstadt (<www.deutsches-polen-institut.de $>$ )

Das seit 1980 tätige Deutsche Polen-Institut Darmstadt (DPI) ist ein Forschungs-, Informations- und Veranstaltungszentrum für polnische Kultur, Geschichte, Politik, Gesellschaft und die deutsch-polnischen Beziehungen, die sich im Kontext der europäischen Integration entwickeln. Institutionelle Träger des DPI sind das Land Hessen, die Kultusminister der Länder, das Auswärtige Amt und die Wissenschaftsstadt Darmstadt. Einen wesentlichen Beitrag zur Verwirklichung der Institutsziele leisten private Stiftungen. Ziel der Vermittlertätigkeit des DPI ist es, »die zu interessieren, auf die es politisch, wirtschaftlich, gesellschaftlich und kulturell im deutsch-polnischen Verhältnis ankommt« (Leitlinien 1997). Es geht um die Entscheider und Multiplikatoren in Politik, Kultur, Bildung, Verwaltung, Medien und Wirtschaft. Das DPI versteht sich in Kooperation mit den Orten wissenschaftlicher Polen-Kompetenz an deutschen Hochschulen und Forschungsinstituten als verbindendes und vernetzendes Zentrum. Mit der über 68.000 Bände zählenden multidisziplinären Fachbibliothek für Polen, die eine einzigartige Sammlung polnischer Belletristik in der Originalsprache und in deutscher Übersetzung umfasst, ist das DPI ein geschätzter Ort der Recherche und des wissenschaftlichen Arbeitens.

Forschungsstelle Osteuropa an der Universität Bremen (<www.forschungsstelle.uni-bremen.de>)

1982 gegründet, widmet sich die Forschungsstelle Osteuropa an der Universität Bremen der interdisziplinären Analyse der Länder Ost- und Ostmitteleuropas in Zeitgeschichte und Gegenwart. Der Forschungsschwerpunkt liegt dabei auf der Rolle von »Dissens und Konsens«, von Opposition und Zivilgesellschaft in ihrem historischen, politischen, gesellschaftlichen und kulturellen Kontext. Die Forschungsstelle besitzt in ihrem Archiv eine einzigartige Sammlung alternativer Kulturgüter und unabhängiger Texte aus den ehemaligen sozialistischen Ländern. Darunter befindet sich auch eine umfangreiche Sammlung des "Zweiten Umlaufs«, die das Schrifttum und Dokumente unabhängiger Initiativen und gesellschaftlicher Gruppen in Polen aus der Zeit von 1976 bis zum Umbruch umfasst. Hinzu kommt eine umfangreiche Bibliothek mit wissenschaftlicher Literatur. Mit Archiv, Bibliothek und zwei wissenschaftlichen Abteilungen ist die Forschungsstelle auch eine Anlaufstelle sowohl für Gastwissenschaftler als auch für die interessierte Öffentlichkeit.

Eine der Hauptaufgaben der Forschungsstelle ist die Information der interessierten Öffentlichkeit. Dazu gehören unter anderem regelmäßige E-Mail-Informationsdienste für Politik, Wirtschaft, Zivilgesellschaft und Medien.

Das Institut für Öffentliche Angelegenheiten (Instytut Spraw Publicznych - ISP) in Warschau ist einer der führenden Think Tanks in Polen und seit 1995 als unabhängiges Forschungszentrum zu grundlegenden Fragen des öffentlichen Lebens tätig. Das ISP kooperiert eng mit zahlreichen Experten und Forschern wissenschaftlicher Einrichtungen im In- und Ausland. $<$ www.isp.org.pl>

Herausgegeben mit finanzieller Unterstützung der Stiftung für deutsch-polnische Zusammenarbeit

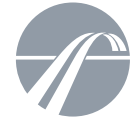

FUNDACJA WSPÓEPRACY
POLSKO-NIEMIECKIEJ

STIFTUNG
FUR DEUTSCH-POLNISCHE

FÜR DEUTSCH-POLNISCHE
ZUSAMMENARBEIT

Die Meinungen, die in den Polen-Analysen geäußert werden, geben ausschließlich die Auffassung der Autoren wieder. Abdruck und sonstige publizistische Nutzung sind nach Rücksprache mit der Redaktion gestattet. Redaktion: Prof. Dr. Dieter Bingen (verantwortlich) (Darmstadt), Silke Plate M.A. (Bremen) Technische Gestaltung: Matthias Neumann

Polen-Analysen-Layout: Cengiz Kibaroglu, Matthias Neumann

Alle Ausgaben der Polen-Analysen sind mit Themen- und Autorenindex archiviert unter www.laender-analysen.de

ISSN 1863-9712 @ 2017 by Deutsches Polen-Institut Darmstadt, Forschungsstelle Osteuropa an der Universität Bremen und Deutsche Gesellschaft für Osteuropakunde e.V. Kontakt: Dr. Andrzej Kaluza, Presse- und Öffentlichkeitsarbeit, Deutsches Polen-Institut, Residenzschloss, Marktplatz 15, 64283 Darmstadt, Tel.: +49/6151/4202-20, Fax: +49/6151/4202-10, E-Mail: polen-analysen@dpi-da.de, Internet: www.laender-analysen.de/polen 